\title{
Position of Wh-Words in Kipsigis Wh-Questions
}

Chepngetich Anastasia

Teacher of English and Literature

Muthambi Boys High School

Chogoria, Kenya

Gatakaa Ann Hidah Kĩnyua

Lecturer of English and Linguistics

Chuka University

Chuka, Kenya

Muriungi Peter Kinyua

Lecturer of English and Linguistics

Tharaka University College

Kenya

anstacy9@gmail.com

\begin{abstract}
The wh-parameter determines whether the wh-expression can be fronted or not. Studies on a number of languages among them English, Shona, Kiitharaka and Chinese have revealed that different languages use different ways to form wh-questions. This paper examines the positions a wh-phrase can occupy in Kipsigis, a southern Nilotic language. A descriptive research design


was adopted and a structure generation exercise was used to elicit data from ten competent native speakers of Kipsigis. Data was analysed within the context of the minimalist program developed by Chomsky. The analysis revealed that Kipsigis wh-words can be found in their canonical position, a position termed in-situ. The wh-words can also be moved to the front of the matrix clause. This movement is triggered by a strong focus feature manifested by a focus marker which is always attached to the verb. The wh-words can undergo partial wh-movement where the whphrase moves to a position lower than its relevant position. The study also established that adjuncts remain in-situ except for the wh-phrase ' why' which can be fronted in addition to being found in-situ. This study contributes towards the understanding of universal and parametric linguistic features in syntactic theory.

Keywords: Wh-in Situ; Wh-ex Situ; Partial Wh-Movement; Topicalization; Wh-fronting; Kipsigis.

\section{Introduction}

Wh-questions are expressions that contain an interrogative word beginning with wh- like what which, who, where, when, why and how. How is treated as a wh-word because it exhibits the same syntactic behavior as other interrogative words beginning with wh- (Radford, 2009). Different languages form wh-questions in various ways which include full wh-movement, partial wh-movement, intermediate strategy and wh-in-situ.

Typically, English uses full wh-movement to form wh-questions. The wh-words move from their underlying positions to the front of the relevant clause. Consider: 
1. Helen took the book. (Object question)

*Helen took what?

What did Helen take?

2. She came in the morning. (Adjunct question)

*She came when?

When did she come?

To form a wh-subject question, the word order is not inverted as in (3) because the whword (who) is the subject of the sentence.

3. James painted the picture. (Subject question)

Who painted the picture?

English subject questions do not require do-support as in (3). English direct questions with non-subject interrogative phrases on the other hand need do-support as in (1) and (2) above. Indirect questions are characterized by the presence of a wh-interrogative at the beginning of the subordinate clause or headed by 'if' or 'whether' (Vermaat, 2006). In such constructions, verbs like 'know', 'wonder' or 'forget' can be merged with an embedded question. As Vermatt (2006) illustrates, embedded interrogatives differ from direct questions in that embedded interrogatives have neither do-support nor subject-auxiliary inversion. This is shown in (4):

(4a) John wondered what Mary saw.

(4b) *John wondered what did Mary see.

(4c) *John wondered what had Mary seen

English has wh-in-situ questions (in form of echo questions) where the wh-expression does not get preposed, but remains in the canonical position associated with its grammatical function as in $(5)$ : 
(5a) She is eating a banana.

(5b) She is eating what?

What here is the direct object complement of eat and since it is a complement it is positioned after the verb eat. According to Radford (2009), English wh-in-situ questions are used as echo questions.

There are instances where questions contain more than one interrogative wh-expression. In such constructions, only one wh- phrase moves. English allows movement of one whexpression where there is more than one wh-expression in the clause. Multiple wh-questions in English are only possible in wh-in-situ and syntactic constructions whose preposed item is 'who'. Consider:

(6a)Who do you think will say what?

$(6 b) *$ What who do you think will say?

Some languages have the wh-words remaining in-situ, a position where we find the corresponding non-wh phrase. Mandarin Chinese, Shona and Kiitharaka are some of the languages that have the wh-words appearing in-situ.

Typically, Mandarin Chinese uses in-situ strategy to form wh-questions

(7) Huăngróngxiāngxìn [cpGuójìngmăileshěnme]?

Huangrong believe Guojing bought what

'What does Huangrong believe that Guojing bought?' (Cheng 2009: 770 (9))

According to Zents (2016) the wh-phrases in Shona remain in-situ.

(8a) V-aka-teng-er-a Ø-aniØ-rokwe? (wh -in situ)

2. SM-TM-buy-APPL-FV 1a-who 5-dress

'Who (m) did they buy a dress (for)?'/ 'They bought who (m) a dress?') 
Other than remaining in-situ, Shona wh-phrases can also undergo full wh-movement and partial wh-movement as in (8b) and (8c).

(8b) Ndi-Ø-aniwa-v-aka-teng-er-a $\varnothing$-rokwe? (Full wh-movement)

NI-1a-who 1a.NSE-2.SM-TA-buy-APL-FV 5-dress

'Who (m) did they buy a dress (for)?'/ ('It's who that they bought a dress (for)?')

(8c) W-ai-fung-a [cpkutindi- $\emptyset$-aniwa-v-aka-teng-er-a (partial wh-movement) 2SG.SM-TA-think-FV that NI-1a-who 1a.NSE-2.SM-TA-buy-APL-FV 'Who (m) did you think they bought a dress (for)?'/ ( 'They thought that it's who that they bought a dress (for)?')

Gichuka, an SVO language, uses full wh-movement, partial wh-movement, wh-in-situ and intermediate strategy to form wh-questions (Mutegi, 2014). In wh-in-situ, the wh-word remains in its canonical position as in $(9 a)$. In $(9 b)$, the wh-word $m b i$ has been moved to the initial position. In intermediate wh-movement, the wh-phrase moves to a position immediately after the subject as in (9c). Partial wh-movement on the other hand is wh-movement in which the wh-phrase undergoes movement, but to a position lower than its relevant position. The scope position itself is occupied by a distinct wh-phrase. In (9d), the wh-word nuu has been displaced but does not move into the matrix clause. This is shown in:

(9a) Kairitu karugire mbi? (Wh-in-situ)

Girl cooked what

'What did the girl cook?'

(9b) Ni mbi kairitu karugire? (Full wh-movement)

FOC-what girl cooked?

'What did the girl cook?' 
(9c) Kairitu nimbi karugire? (Intermediate wh-movement)

Girl FOC-what cooked?

'What did the girl cook?'

(9d) John etikitie nuu mwende augire niarugir e irio? (Partial wh-movement)

John believes FOC-who Mwende said cooked food

'Who does John believe Mwende said cooked the food?

In Kitharaka (which is also a Bantu language spoken in Kenya) the subject, object and adjunct questions allow movement of the wh-phrase to Spec CP of the matrix sentence. This movement of the wh-phrase is accompanied by a focus marker which in this case is a particle $/ n /$ or /i/ (Muriungi, 2003). Apart from full wh-movement represented in (10a) there are other strategies of forming wh-questions, namely: wh-in-situ (10b), partial wh-movement (10c and 10d) and intermediate strategy where the wh-phrase appears immediately after the subject (12e) Muriungi (2005). The bracketed items show the base position occupied by the wh-phrase.

(10a) $N$-uuJohn a-ring-ir-e <uu> (Full wh-movement)

FOC-who John SM-beat-PERF-FV

'Who did John beat?'

(10b) John a-ring-ir-e ( $g) u u($ wh-in situ)

John SM-beat-PERF-FV who

'Who did John beat?'

(10c) G-ug-ir-e atin-uuJohn a-ring-ir-e <uu> (partial wh-movement)

2nd SG-say-PERF-FV that FOC-who John SM-beat-PERF-FV

'Who did you say that John beat?'

(10d) John a-ug-ir-e atikaarigaka, i-mbi Maria a-ka-nenk-e-er-e 
John SM-say-PERF-FV that girl this F-what SM-OM-give-APPL-PERF-FV

'What did John say that this girl, Maria gave to her?'

(10e) John $n$-uua-ring-ir-e <uu> (intermediate strategy)

John F-who SP-beat-PERF-FV

'Who did John beat?'

In Tugen wh-words remain in-situ and are checked covertly at Logical Form (LF) (Jerono, 2012). The wh-elements are positioned immediately after the verb (11a) or sentence finally (11b). The CP position is not created because the subject which is a wh-element remains in-situ at SPEC/VP.

(11a) Ø -wéénd-í ánó láákw-éé?

3SG-go-IMP where child-SG/DEF

'Where is the child going?'

(11b) Kà -ø- áàl-ø Kí-mórú kàláámí-t ngìró?

PST-3SG-buy-3OB M-moru pen-SG/DEF which

'Which pen did Kimoru buy?'

Nandi allows no wh-movement but has in -situ questioning of both subjects and objects Creider (1989). The study investigated and documented the positions a wh-word can occupy in Kipsigis wh-questions.

\section{Theoretical Framework}

The study was informed by the principles and parameters theory which recognizes that languages are acquired in much the same way, but vary systematically. The minimalist program, which is an outgrowth of the principles and parameters theory, was used in analyzing the data. 


\section{Materials and Methods}

This work is qualitative as it deals with words, phrases and sentences. The research design is descriptive as it describes the positions in which wh-words are found. The study involved Kipsigis native speakers. Purposive sampling was used to identify competent respondents who had to have completed form four level of education for them to understand what was required. Data was elicited through the use of a structure generation exercise which was administered to ten competent native speakers of Kipsigis. Native speaker intuition was then used to judge the grammaticality and acceptability of the responses. Data was analysed in tree diagrams using the minimalist sentence structure.

\section{Results and Discussion}

Kipsigis is a subgroup of the Kalenjin language which is a Nilotic language spoken in the western highlands of the Rift Valley. Kipsigis is spoken by roughly two million people (Lewis.et al. 2016). It is a verb initial language with VSO/VOS word order. The VOS word order is a result of the object shifting to the left so that it intervenes between the verb and the subject. The verb always comes first while the subject and object can trade places:

12. Katyaar Kibet mpiret (VSO)

Kicked Kibet the ball

'Kibet kicked the ball'

13. Katyaar mpiret Kibet (VOS)

Kicked the ball Kibet

'Kibet kicked the ball' 


\subsection{Subject Wh-questions}

The subject wh-questions are formed by the wh-phrases who, what, whose and whom. These are: $n g$ 'oo, nee, apng'oolpong'ooand $n g$ 'oo in Kipsigis respectively. In Kipsigis there are two positions termed in-situ because of the VSO/VOS word order alternation. When the whphrase comes after the verb, it creates VSO word order as in (14a). When the wh-phrase comes sentence-finally it creates a VOS word order as in (14b). In (14b), the wh-phrase ' $n g$ 'oo' appears after the verb 'koip'.

(14a) Koip ng'oo kilamit nyuun? (VSO)

Took who pen mine

'Who took my pen?'

(14b) Koip kilamit nyuun ng'oo? (VOS)

Took pen mine who?

'Who took my pen?'

The wh-phrase can also be moved to the front of the sentence. This movement is accompanied by a focus marker ' $n e$ ' which is attached to the verb.

(14c) Ng'oo ne-koip kilamit nyuun?

Who F-took pen mine?

'Who took my pen?'

Movement of the wh-phrase without addition of a focus marker results in ungrammaticality as in;

$(14 d) * N g ' o o$ koip kilamit nyuun?

Who took pen mine?

'Who took my pen?'

Whose is another phrase representing the subject wh-questions. Consider: 
(15) Konyo ng'etapkamitap John amut.

Came brother John yesterday

'John's brother came yesterday'

The sentence in (15) can be questioned in the following ways:

(16a) Konyo ng' etapkamit apng'oo amut? (In-situ)

Came brother whose yesterday?

'Whose brother came yesterday?'

(16b) Ng'etapkamit apng'oo ne-konyoamut (ex-situ)

Brother whose came yesterday?

'Whose brother came yesterday?'

The construction in (16b) demonstrates the ex-situ strategy because movement has occurred so that the wh-phrase apng 'oo(whose) now comes before the verb nekonyo(came). The construction also conforms to the fact that when movement occurs, a focus marker must be attached to the verb. In this way, Kipsigis behaves like Gichuka and Kitharaka where movement of the wh-phrase is accompanied by a focus marker. In this case, the focus marker ' $n e$ ' is attached to the verb 'konyo'. The construction in (15) can also be questioned in the form:

(16c) Ne-konyo amut ko ng' etapkamitap ng'oo?

'The person that came yesterday is whose brother?'

In (16c), topicalization has been employed in asking the question 'whose brother?' The topic of the sentence is 'ne-konyoamut' which is equivalent to 'the person that came yesterday'. It forms the subject of the sentence. From the construction it is evident that topicalization is an instance of focusing because of the focus particle ' $n e$ ' which is attached to the verb konyo. It is also true to say that topicalization is an instance of clefting. The construction in (16c) is a 
pseudo-cleft construction whereby the subject (the person that came yesterday) is a nominalized relative clause and the wh-phrase (whose brother) is the predicate.

In a complex sentence, the facts are essentially the same as those of simple sentences. Consider:

(17) Kole Tom kamut Kipkoech lakweet

Said Tom took Kipkoech the child

'Tom said Kipkoech took the child'

The subject of the complex sentence can be questioned in the following ways;

(18a) Kole Tom kamut ng'oo lakweet? (In-situ: wh-phrase appearing after the verb)

Said Tom took who the child?

'Who(m) did Tom say took the child?'

(18b) Kole Tom kamut lakweet ngoo? (In-situ: the wh-phrase coming sentence finally)

Said Tom took child who?

'Whom did Tom say (that) took the child?'

(18c) Ng'oo ne-kole Tom kamut lakweet? (Ex-situ: Focusing)

'Whom did Tom say (that) took the child?'

(18d) Kole Tom ng'oo ne-kamut lakweet? (Partial wh-movement)

Said Tom who F-took the child?

'Who(m) did Tom say (that) took the child?'

(18e) Ne-kole Tom kamut lakweet ko ng'oo? (Topicalization)

The person Tom said took the child is who?

'Who is the person Tom said took the child?

In (18a) and (18b) the wh-phrase occupies the in-situ position. In (18a), the wh-phrase appears after the verb in the embedded clause, while in (18b) the wh-phrase comes sentence 
finally. (18c) on the other hand is an instance of wh-movement because the wh-phrase has been moved to the left periphery and there is a focus marker attached to the verb. On the other hand (18d) displays partial wh-movement. Partial wh-movement is wh-movement in which the whphrase undergoes movement but to a position lower than its relevant position (Saddy, 1991). In (18d), the wh-phrase $n g$ 'oomoves to a structurally lower position other than the matrix clause. (18e) is a pseudo-cleft construction where the wh-phrase is the predicate and the subject is 'The personTom said took the child'. It is an instance of topicalization where the particle ' $k o$ ' is used. Pseudo-cleft constructions are also used to form wh-questions in Polynesean languages (Potsdam and Polinsky, 2011).

\subsection{Object Wh-Questions}

Consider:

(19a) Kaam John kimnyeet (VSO)

Ate John ugali

'John ate ugali'

(19b) Kaam kimnyeet John (VOS)

Ate ugali John

'John ate ugali.'

In (19a) and (19b), the object of the sentence is kimnyeet(ugali). The object can be questioned in the following ways:

(20a) Kaam John nee? (In-situ: the wh-phrase coming sentence finally) Ate John what?

'What did John eat?'

(20b) Kaam nee John? (In-situ: the wh-phrase coming after the verb) 


\section{Ate what John?}

'What did John eat?'

(20c) Nee ne-kaam John? (Ex-situ)

What eat John?

'What did John eat?'

The constructions in (20a) and (20b) indicate the use of the in-situ strategy where the whphrase appears sentence finally and after the verb respectively. With the in-situ strategy, there is no focus marker. In (20c), there is movement of the wh-phrase 'nee' to the left periphery and there is the focus marker ' $n e$ ' which is attached to the verb ' $k a a m$ '. This therefore is an instance of ex-situ strategy. Wh-movement without the focus marker yields ungrammaticality as in (20d):

(20d) *Nee kaam John?

What ate John?

'What did John eat?'

In a complex sentence, the object wh-phrase can be questioned in- situ as in (23a):

(22a) Kele kiialde ngoriet ainon?

You said you sold dress which?

'Which dress did you say you sold?'

The wh-phrase 'ainon' (which) comes sentence-finally, indicating the in-situ strategy. Furthermore, there is no focus marker.

The wh-phrase can also be moved from its base position to a position lower than the matrix clause. This is where the wh-phrase appears in the embedded clause. (22b) is an instance of partial wh-movement because the wh-phrase has left its base position and has not moved to the front of the matrix clause but to the front of the embedded clause. 
(22b) Kele aimon ngoriet ne-kiialde?

You said which dress you sold?

'Which dress did you say you sold?'

The constructions in (22c) and (22d) demonstrate the ex-situ strategy because the whphrases are moved to the front of the matrix clause.

(22c) Ngoriet ainon ne-kele kiialde?

Dress which you said you sold?

'Which dress did you say you sold?'

In (22c), the wh-phrase 'ainon' (which) is a post modifier of 'ngoriet' (dress). In (22d), 'ngoriet' is the complement of the wh-phrase 'ainon'. We can therefore say when the wh-phrase moves, it drags along its complement through the process called pied piping.

(22d) Ainon ngoriet ne-kele kiialde?

'Which dress did you say you sold?'

Topicalization can also be used in object wh-questions as in the construction in (22e):

(22e) Ngoriet nekele kiialde ko ainon?

Dress that you said you sold is which one?

'The dress that you said you sold is which one?'

The subject of the sentence in (22e) is 'ngoriet nekele kiialde' (the dress that you said you sold) and the predicate is 'ainon' (which one). Topicalization in Kipsigis involves the use of the particle ' $k o$ ' to link the subject to the predicate. 


\subsection{Adjunct Wh-Questions}

Adjunct wh-questions answer the questions how, when, where and why. These are ano, $a u$, ano and kalyaan/amunee respectively. Kipsigis is a tonal language in the sense that tone is used to differentiate lexical items. Yip (2002) says a language with tone is one which an indication of pitch enters into the lexical realization of at least some morphemes. According to Toweett (1975), there are four main tones in Kipsigis: low tone, high tone, high falling tone and low-rising tone (which is rare). A lexeme such as the adjunct 'ano' has two meanings: 'ano'(where) which is said with a high tone and 'ano' (how) which is said with a low tone

How

Consider:

(23) Kaamis Chepng'eno mutyo

Ate Chepng'eno slowly

'Chepng' eno ate slowly.'

The wh-expression how can be questioned in the following way;

(24a) Kaamisyoito ano Chepng' eno?

Ate how Chepng'eno

'How did Chepng' eno eat?'

The answer to (24a) above would be mutyo (slowly). The adjunct wh-phrase how cannot be questioned ex-situ as this would yield ungrammaticality as seen in (24b);

(24b) *Ano kaamis Chepng'eno?

How ate Chepng'eno

'How did Chepng' eno eat?' 
When

Consider:

(25) Nyone John karon

Coming John tomorrow

'John is coming tomorrow.'

The wh-phrase when (au) can be questioned in the following ways:

(26a) Nyone au John? (In-situ; after the verb)

\section{Coming when John?}

'When is John coming?'

(26b) Nyone John au? (In-situ; sentence finally)

\section{Coming John when?}

'When is John coming?'

The constructions in (26a) and (26b) exemplify the in-situ strategy because the wh-phrase ' $a u$ ' (when) comes after the verb and sentence-finally respectively. Further when the wh-phrases remain in-situ there is no focus marker. An attempt to move the wh-phrase $a u$ (when) results in ungrammaticality can be seen in (26c);

(26c) *Au nyone John?

When coming John?

'When is John coming?'

In a complex sentence the adjunct wh-phrase ' $a u$ ' (when) can be questioned in-situ. Consider:

(27a) Kale Cherono inome tiemutik karon Said Cherono begin the exam tomorrow 
'Cherono said (that) the exam will begin tomorrow'

The adjunct wh-phrase $a u$ (when) can come after the verb in the embedded clause as in (27b);

(27b) Kale Cherono inome au tiemutik?

Said Cherono FUT-begin when the exam?

'When did Cherono say the exam will begin?'

The adjunct wh-phrase $a u$ (when) can come sentence finally as in $(27 \mathrm{c})$;

(27c) Kale Cherono inome tiemutik au?

Said Cherono FUT-begin the exam when?

'When did Cherono say the exam will begin?'

Where

The adjunct wh-phrase 'ano' (where) can also be questioned in-situ. Consider (28);

(28) Kale John kawa oinet Peter.

Said John go river Peter.

'John said (that) Peter went to the river.'

The adjunct wh-phrase 'ano' (where) can come after the verb in the embedded clause as in (29a);

(29a) Kale John kawa ano Peter?

Said John go where Peter?

'Where did John say Peter went?'

The adjunct wh-phrase 'ano' (where) can come sentence finally as in (29b);

(29b) Kale John kawa Peter ano?

Said John go Peter where?

'Where did John say Peter went?' 
Like the adjunct wh-phrases how and when, the wh-adjunct phrase where cannot be questioned ex-situ as this will yield ungrammaticality as seen in (29c):

(29c) * Ano kale John kawa Peter

Where said John went Peter

'Where did John say Peter went?'

The observation made here is that there is no focus marker in the formation of the wh-question, implying that movement does not occur but the wh-phrase remains in-situ.

Why

The wh-phrases used to ask the question why in Kipsigis are 'kalyaan' and 'amunee'. Consider:

(30a) Kanyo John kokachelewan amun kameto bussit.

Came John late because he was left by the bus.

'John came late because the bus left him'

The adjunct wh-phrase ' why' (amunee) can be questioned in-situ as in (30b);

(30b) Kanyo John kokachelewan amunee?

Came John late why?

'Why did John come late?'

The adjunct wh-phrase why can also come at the beginning of the question as in (30c) and (30d);

(30c) Kalyaan asikonyo John kokachelewan?

Why came John late?

'Why did John come late?'

(30d) Amunee asikonyo John kokachelewan?

Why came John late? 
'Why did John come late?'

The wh-phrase 'why' can be questioned in-situ as in (30b) above. It can also appear at the beginning of the sentence as in (30c) and (30d). However, the instance where the wh-phrase 'why' appears at the front of the sentence cannot be termed an instance of focusing as with the case of wh-movement because there is no focus marker. This is herein referred as wh-fronting.

\subsection{Multiple Wh-Questions}

Multiple questions occur in Kipsigis whereby two wh-phrases can remain in-situ. This is unlike the case in English where one wh-expression can be found in situ while the other is preposed. In English, 'who' is the only wh-expression that can be preposed. Kipsigis being verb initial has the verb coming first followed by the interrogative words. Consider:

(31) Kaal ng'oo nee

Bought who what

'Who bought what?'

(32) Kayai ng'oo nee

Do who what

'What did who do?'

(33) Ipwote ile wendi ng'oo ano

You think go who where

'Who do you think will go where?'

The interrogative words $n g$ 'oo(who), nee (what) and ano(where) are positioned after the verb indicating that they remain in-situ. One of the wh-phrases can also be moved to the left 
periphery which in this case is the ex-situ position. In the movement of the wh-phrase, a focus marker ' $n e$ ' must be attached to the verb as in (34):

(34a) Ng'oo ne-kakeer nee?

'Who saw what?'

(34b) Nee ne-kaal ng'oo?

What bought who?

'Who bought what?'

From the examples in (34), the wh-phrases ng'oo (who) and nee (what) can be preposed to yield a grammatical structure. An attempt to move the two wh-phrases results in ungrammaticality as in (35):

(35) *Ng'oo nee kakeer?

Who what saw?

'Who saw what?'

The adjunct interrogatives how and when cannot be moved to the left periphery but they remain in-situ.

(36) Kawentito ng'oo ano?

Walked who how?

'Who walked how?'

(37) Kanyo ng'oo au?

Came who when?

'Who came when?'

In (36) and (37) it is possible to move the wh-phrase $n g$ 'oo(who) to the left periphery but movement of the wh-phrases ano(how) and $a u$ (when) is not possible. 


\subsection{Indirect Questions}

Indirect questions in Kipsigis are characterized by the interrogative word coming after the verb in the subordinate clause or sentence finally. Consider:

(38) Kakwong' John kole kakeer nee Mary (Interrogative word coming after the verb)

Wondered John saw what Mary

'John wondered what Mary saw'

(39) Akwong'e ale kogawa ano (Interrogative word coming sentence finally)

I wonder she had gone where

'I wonder where she had gone to'

(40) Katepenan kole kaal nee (Interrogative word appearing sentence finally)

She asked me I bought what

'She asked me what I had bought'

In (38), the interrogative word 'nee' comes after the verb in the subordinate clause, whereas in (39) and (40) the interrogative words 'ano' and 'nee' respectively are positioned sentence finally. These three instances demonstrate the wh-in-situ positions because the whphrase comes after the verb and sentence finally. The construction in (40) can also appear in the form presented in (41):

(41) Katepenan kiit ne-kaal

'She asked me what I had bought'

In (41) movement must have occurred because the wh-phrase 'nee' which has been replaced by the phrase 'kiit' has moved from the sentence final position to a position preceding the embedded clause what I had bought. There is also a focus marker (ne) which is attached to the verb 'kaal'. 


\subsection{Structural Representation of Kipsigis Wh-questions}

According to Chomsky (1993) the basic minimalist program sentence structure is as follows;

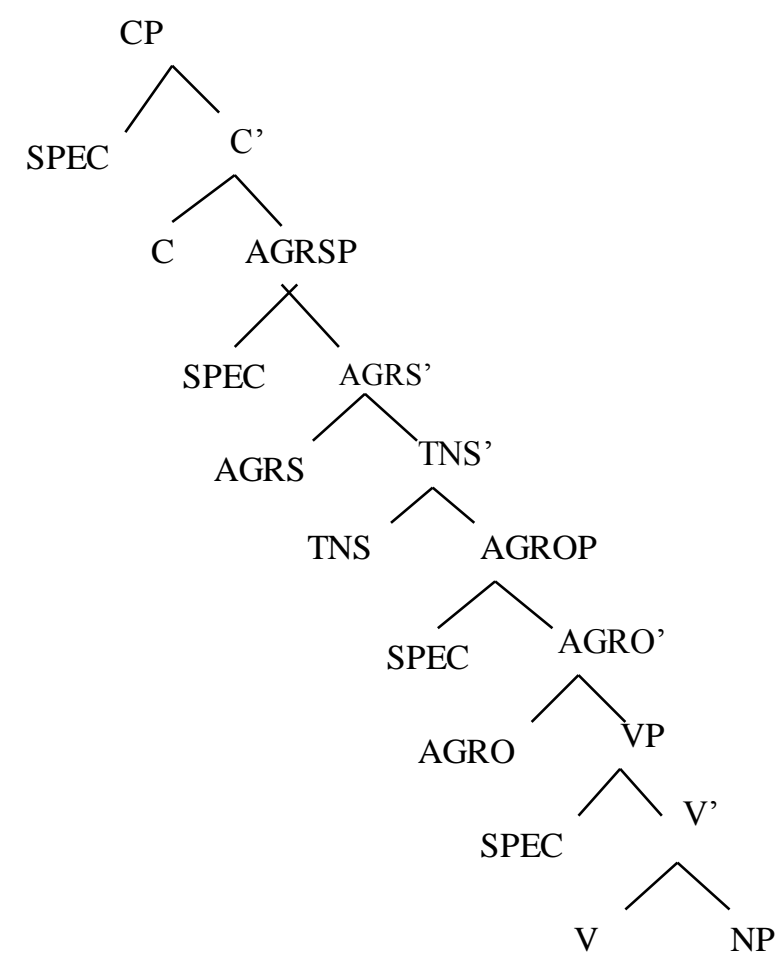

Figure 1. The minimalist sentence structure (Chomsky, 1993).

The above structure is built in a bottom up process that involves the combination of lexical and morphological features through the process of select and merge in the lexicon. Morphological features like tense and agreement are selected and merged with the verb and the verb selects and merges with other constituents like noun phrases in the building up of the sentence structure. In SVO languages like English, the verb moves to AGRS to check agreement features while the subject moves to SPEC /AGRSP to check for nominative case. In that case the subject heads the sentence. The structure therefore does not cater for verb initial languages with 
VSO/VOS word order (Jerono, 2012). She therefore designs a way in which such languages can be accommodated.

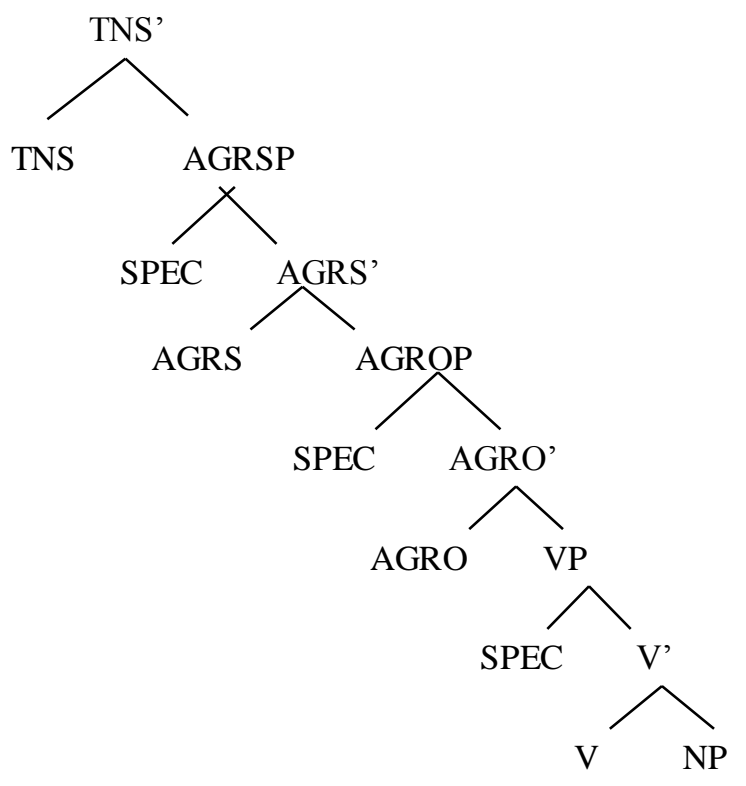

Figure 2. The minimalist sentence structure for verb initial languages (Adopted from Jerono (2012))

In the above structure the verb moves from the VP then to AGRO' to check for agreement object features then to AGRS' to check for agreement subject features and finally to TNS to check for tense features. The subject moves from SPEC/VP to SPEC/AGRSP to check for nominative case features. The object moves from the VP to SPEC/AGROP for accusative case checking. This sentence structure has been adopted in the structural analysis of Kipsigis whquestions since Kipsigis is a verb initial language.

Wh-in situ

In this strategy, the wh-word does not move. Instead, the wh-words remain in the position normal for subjects, objects and adjuncts. 


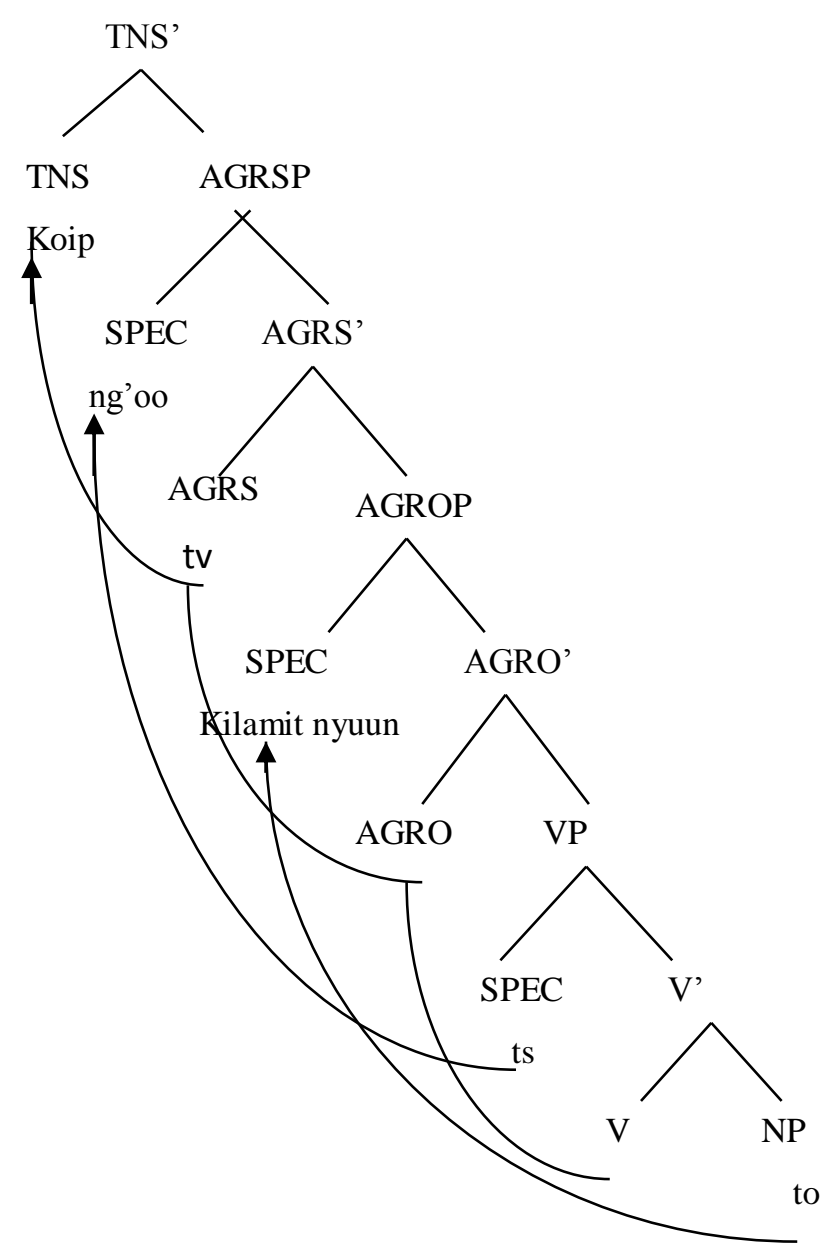

Figure 3. Subject wh-question

In this structure, the subject wh-element $n g$ 'oo is base generated at specifier of VP then moves to SPEC/AGRSP position.

Wh-ex-situ

Wh ex-situ occurs when the wh-word is moved to specifier position of the matrix sentence. In figure 4, the wh-element $n g$ 'oo moves from SPEC/AGRSP to SPEC/FOCP position to check for focus features. This is supported by the claim put forth by Sabel (2009) that whmovement is triggered by a strong [+focus] feature in a functional head (Foc). This focus feature in Kipsigis is manifested morphologically by a focus marker ' $n e$ '. 


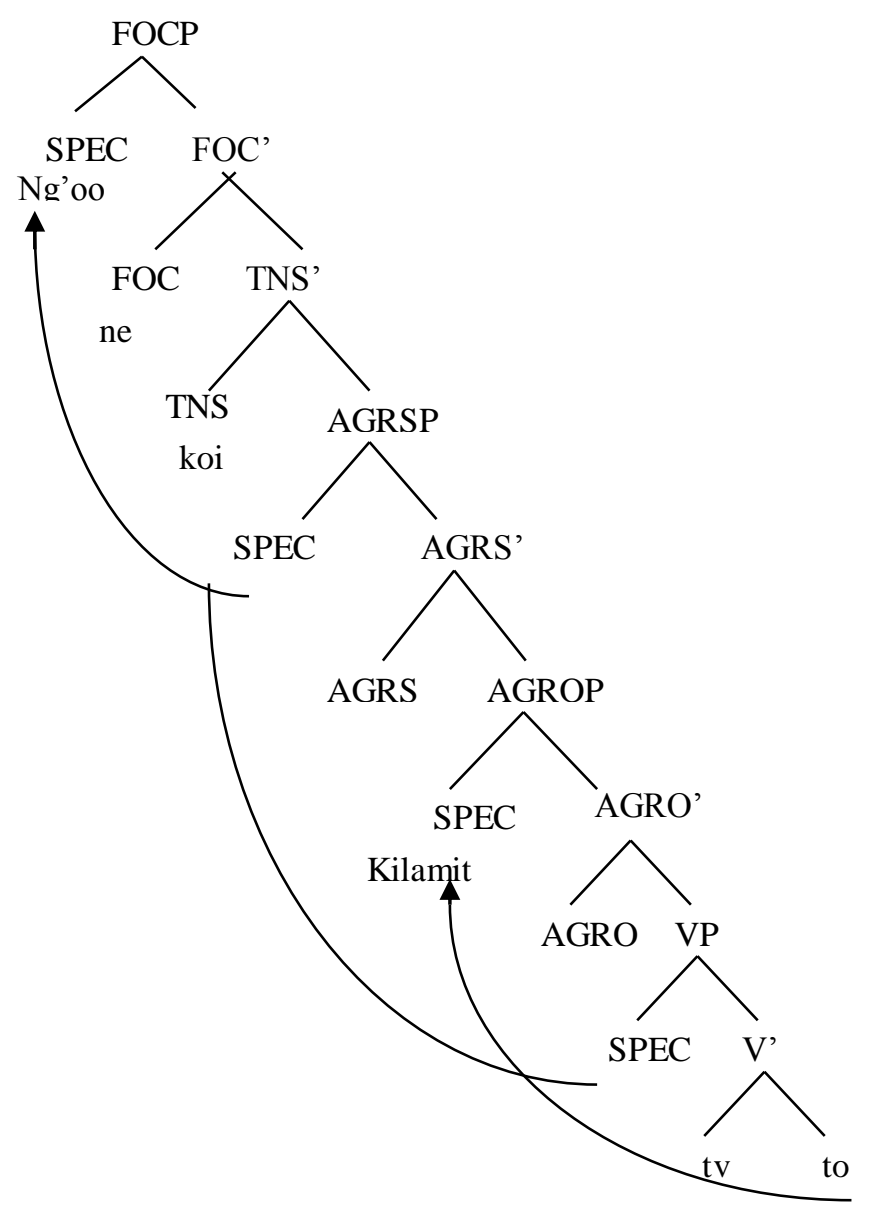

Figure 4. Ex-situ

\section{Partial wh-movement}

Partial wh-movement occurs when the wh-phrase leaves its base position but does not move to the matrix clause. It is an instance of movement and therefore, in Kipsigis, a focus marker must be attached. Both subjects and objects display partial wh-movement. 


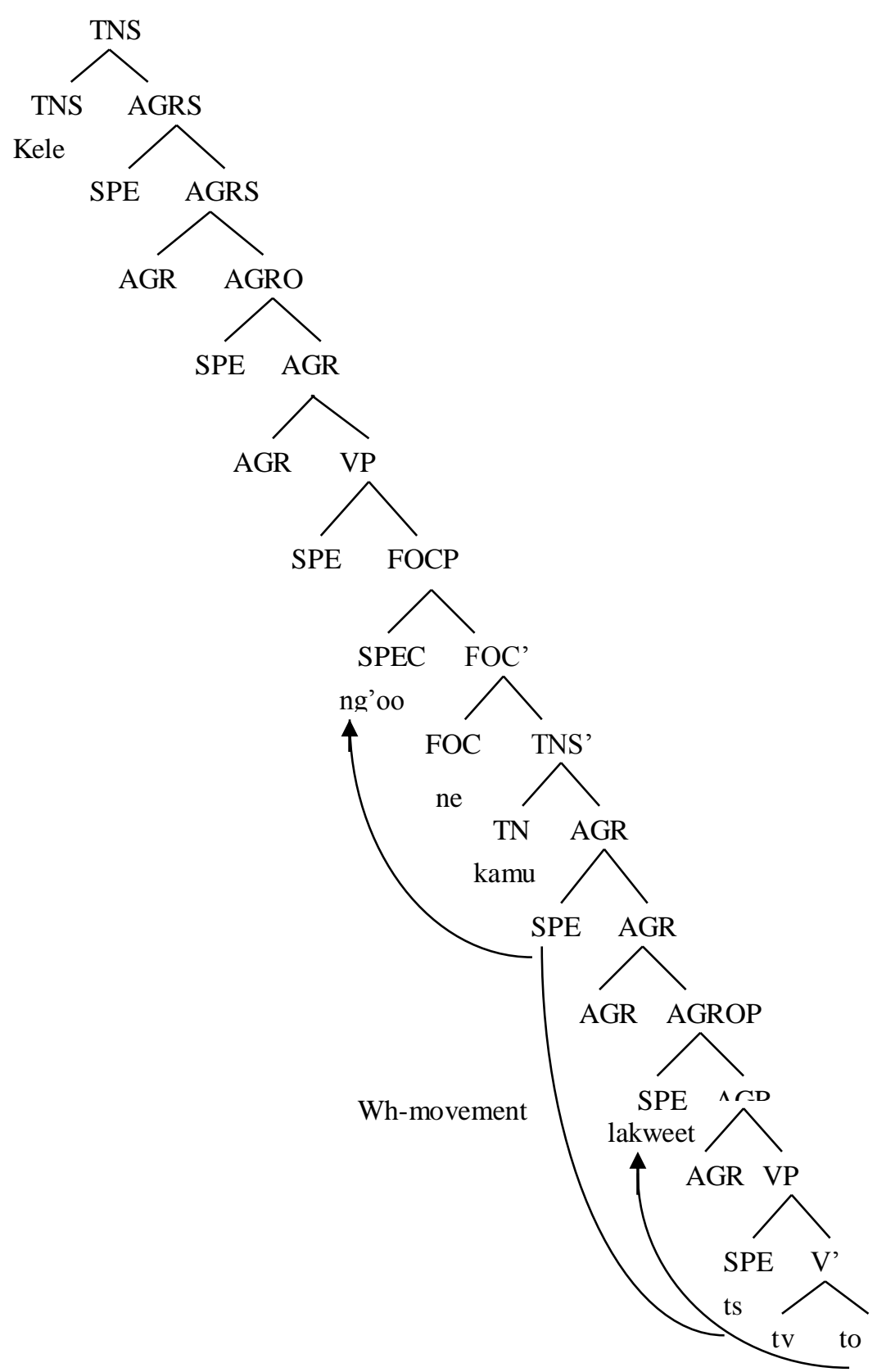

Figure 5. Partial wh-movement

\section{Conclusion}

In conclusion, the subject and object wh-words can be found in-situ; after the verb or sentence finally. They can also be found at the front of the matrix clause, a position termed ex- 
situ. Adjuncts are found in-situ except for the adjunct wh-phrase 'why' which can also be fronted. In multiple questions, two wh-words can be found in-situ while on the other hand; one wh-word can be moved to the front of the interrogative sentence. In indirect questions the whwords come after the verb in the subordinate clause or sentence finally. They can also be moved in a construction where the verb asked is merged with an embedded question. 


\section{References}

Chomsky, N. (1993). A Minimalist Program for Linguistic Theory. MIT Occassional Papers in Linguistics 1. MIT Press Cambridge.

Creider,C.A (1989). The Syntax of Nilotic Languages: Themes and Variations. Dietrich Reimer, Berlin.

Jerono, P. (2012). Tugen Word Order. A Minimalist Perspective. Egalite Macedonia.

Lewis, et.al. (2016). Ethnologue: Languages of the World, nineteenth edition, Dallas, TX.

Muriungi, P.K. (2003). Wh-questions in Kitharaka. University of Witwatersrand, Johannesburg.

Mutegi, M.K. (2014). Strategies of Forming wh-questions in Gichuka. MA Dissertation, Chuka University.

Potsdam, E. \&Polinsky, M. (2011). Questions and Word Order in Polynesean. Topics in Oceanic Morphosyntax, pages 121-153.

Radford, A. (2009). Analyzing English Sentences. A Minimalist Approach. Cambridge University Press, New York..

Sabel, J. (2000). Partial Wh-movement and the Typology of Wh-questions. In Wh-Scope Marking, 404-449. John Benjamins, Amsterdam.

Saddy, D. (1991). Wh-Scope Mechanism in Bahasa Indonesia. MIT Working Papers in Linguitics 15.MIT Press, Cambridge.

Toweet, T. (1975). Kalenjin Nouns and their Classification. UoN, Unpublished M.A Dissertation.

Vermaat, W. (2006). The Logic of Variation. A Cross Linguistic Account of Wh-question Formation. Landelijke Onderzoek school Taalwetenschap.

Yip, M. (2002). Tone. Cambridge University Press, Cambridge. 
Zents, J. (2016). Forming Wh-questions in Shona. A Comperative Bantu Perspective. Phd Dissertation, Yale Univeristy. 